Prepared for the U.S. Department of Energy under Contract DE-AC05-76RL01830

\title{
Initial Decision and Risk Analysis
}

\author{
DW Engel
}

February 2012

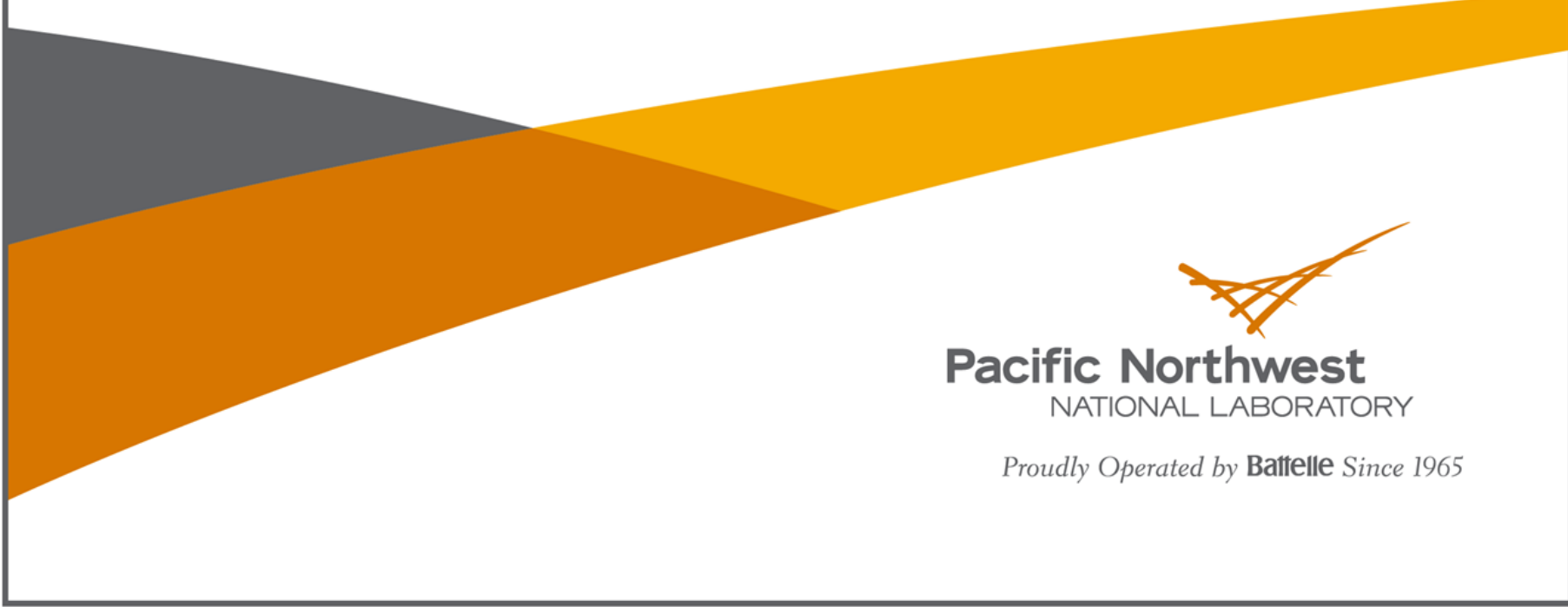




\title{
DISCLAIMER
}

This report was prepared as an account of work sponsored by an agency of the United States Government. Neither the United States Government nor any agency thereof, nor Battelle Memorial Institute, nor any of their employees, makes any warranty, express or implied, or assumes any legal liability or responsibility for the accuracy, completeness, or usefulness of any information, apparatus, product, or process disclosed, or represents that its use would not infringe privately owned rights. Reference herein to any specific commercial product, process, or service by trade name, trademark, manufacturer, or otherwise does not necessarily constitute or imply its endorsement, recommendation, or favoring by the United States Government or any agency thereof, or Battelle Memorial Institute. The views and opinions of authors expressed herein do not necessarily state or reflect those of the United States Government or any agency thereof.

\author{
PACIFIC NORTHWEST NATIONAL LABORATORY \\ operated by \\ BATTELLE \\ for the \\ UNITED STATES DEPARTMENT OF ENERGY \\ under Contract DE-AC05-76RL01830
}

Printed in the United States of America
Available to DOE and DOE contractors from the Office of Scientific and Technical Information,
P.O. Box 62, Oak Ridge, TN 37831-0062;
ph: (865) 576-8401
fax: $(865)$ 576-5728
email: reports@adonis.osti.gov

\begin{abstract}
Available to the public from the National Technical Information Service, U.S. Department of Commerce, 5285 Port Royal Rd., Springfield, VA 22161 ph: (800) 553-6847 fax: $(703) 605-6900$ email: orders@ntis.fedworld.gov online ordering: http://www.ntis.gov/ordering.htm
\end{abstract}

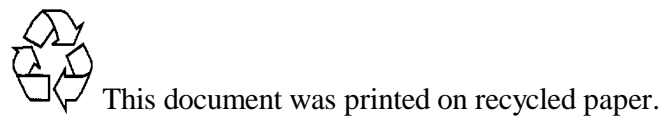




\section{Initial Decision and Risk Analysis}

DW Engel

February 2012

Prepared for

the U.S. Department of Energy

under Contract DE-AC05-76RL01830

Pacific Northwest National Laboratory

Richland, Washington 99352 



\section{Contents}

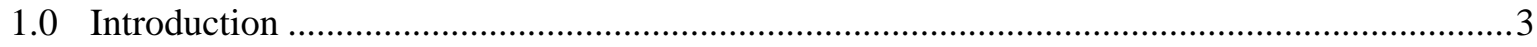

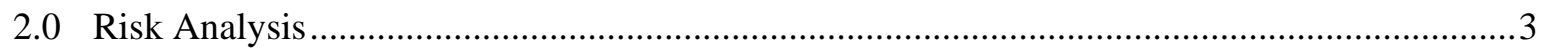

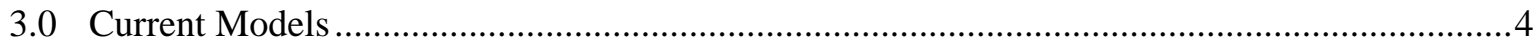

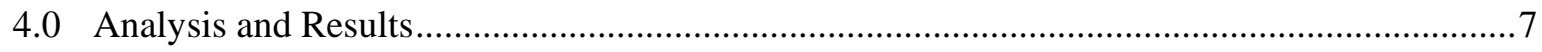

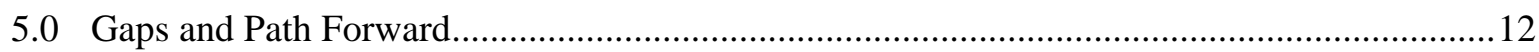

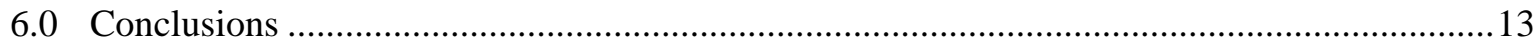

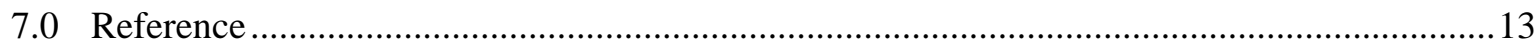

\section{Figures}

Figure 1 TRL uncertainty model and example using COE from the process modeling task...........6

Figure 2 Input marginal distributions for the stochastic parameters ............................................

Figure 3 Distribution of discounted net present value of net receipts for the carbon case -

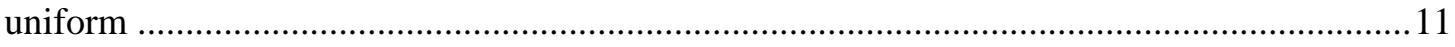

Figure 4 Distribution of discounted net present value of net receipts for the carbon case - non-

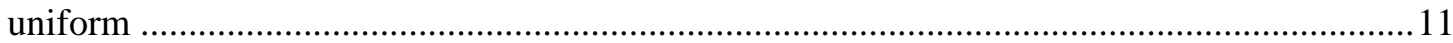

Figure 5 Sensitivity analysis of the NPV, represented by the scatterplots of each NPV-parameter12

\section{Tables}

Table 1 Proposed TRL scale for carbon capture ....................................................................

Table 2 CC system specific parameters: changed under Cases A and B ....................................

Table 3 Initial financial, operating, and market assumptions....................................................... 7 


\subsection{Introduction}

Commercialization of new carbon capture simulation initiative (CCSI) technology will include two key elements of risk management, namely, technical risk (will process and plant performance be effective, safe, and reliable) and enterprise risk (can project losses and costs be controlled within the constraints of market demand to maintain profitability and investor confidence). Both of these elements of risk are incorporated into the risk analysis subtask of Task 7. Thus far, this task has developed a prototype demonstration tool that quantifies risk based on the expected profitability of investments to retrofit carbon capture technology on a stylized $650 \mathrm{MW}$ pulverized coal electric power generator. The prototype is based on the selection of specific technical and financial factors believed to be important determinants of the expected profitability of carbon capture, subject to uncertainty. The uncertainty surrounding the technical performance and financial variables selected thus far is propagated in a model that calculates the expected profitability of investments in carbon capture and measures risk in terms of variability in expected net returns from these investments. Ultimately, this tool will allow for analysis of the financial risks associated with adopting carbon capture technology from the perspective of decision makers at utilities.

This report satisfies the final milestone for Task 7 of the CCSI program. This milestone is defined as the following:

\section{Milestone 7-2}

Decision and Risk Analysis capabilities will be developed for industry consideration and possible adoption within Year 1. These tools will provide a methodology for merging qualitative ranking of technology maturity and acknowledged risk contributors with quantitative metrics that drive investment decision processes. Methods and tools will be initially introduced as applications to the A650.1 case study, but modular spreadsheets and analysis routines will be offered to industry collaborators as soon as possible to stimulate user feedback and co-development opportunities.

\subsection{Risk Analysis}

The analysis of risk directly feeds into the risk management process. During this project, one of the objectives will be to identify the requirements and the processes for securing the confidence of capital investors who must ultimately accept the residual risk remaining after simulation and analysis of technology scale-up has been performed. The process of "Risk Management" must be equated with the desired end result of "Risk Acceptance." Traditionally, risk communication is relegated to a standalone activity that focuses heavily on community outreach and translation of formal quantitative results into common terms that stakeholders relate to more naturally. The CCSI project affords an opportunity to build in risk communication from the outset by tailoring the risk analysis methodology to the interests of the capital investment community. This focus does not preclude nor replace the ultimate need for gaining widespread public acceptance of sequestration activities, but it aligns more closely with the present scope of the CCSI. Risk analysis should be integrated with process simulation and optimization efforts rather than being applied as a post-processing activity. For example, residual uncertainties in predefined risk acceptance criteria (like cost) should be diagnosed to determine the principal process-level contributors to this uncertainty. Plant simulations can be modified, or additional calculations can be performed to reduce these uncertainties from the parameter space in order to improve confidence in final decision metrics.

\section{Financial Risk}

In any large project, financial risks should be estimated as precisely as possible to minimize the possibility that even small miscalculations result in severe and irreparable losses to entrepreneurs, investors, financiers and society in general. High risks associated with uncertainties regarding the cost 
structure of project construction, materials, workforce, engineering questions and instability in market values.

\section{Technical Risk}

The elements of technical risk are not easily characterized, since real technical risk involves a forecast of how science will pan out when real people conduct experimentation, interpret results, and apply them in real situations. The elements of technical risk are not independent of one another: actions to understand and mitigate risk are interrelated through the laws of science, patterns of rational processes, and the personalities of people involved.

The difficulty of quantifying the uncertainties associated with early-stage technical projects is only one of the conceptual difficulties with a statistically based definition of technical "risk." A second difficulty is that technical projects tend to have binary outcomes: they are either terminated when they encounter severe obstacles or are supported all the way to market introduction (perhaps with modifications in both technology and market objective). An important attribute of risk-taking is that it is deliberately undertaken because the rewards, multiplied by the (presumably known or estimable) probability of achieving those rewards, exceed the cost of taking the risk.

\section{Regulatory Risk}

Regulatory risk embodies costs and uncertainties associated with additional, and in some cases, unanticipated, regulatory burdens that can reduce earnings and increase the financial risk associated with investments in carbon capture technology.

\section{Investor Attitudes Towards Risk}

Investor attitudes towards risk are an important determinant of how investors respond to risk and how investors respond to the trade-off between profitability and risk. It is likely that utility investors display more aversion towards risk than investors in other industries. This applies to financial risk and to technical risk since reliability of system performance will be an important consideration when evaluating investments in carbon capture technology.

\subsection{Current Models}

Thus far, this task has developed a prototype demonstration tool that quantifies risk based on expected profitability of expenditures and variation in profits to retrofit carbon capture technology on a stylized $650 \mathrm{MW}$ pulverized coal electric power generator (Letellier et al., 2011). The prototype is based on the selection of specific technical and financial factors believed to affect the expected profitability of investments in carbon capture, subject to uncertainty. The uncertainty surrounding the technical performance and financial variables selected thus far is propagated in a model that calculates the expected profitability of investments in carbon capture and measures risk in terms of variability in expected net returns from these investments.

\section{Financial risk model}

The approach requires translating technical and financial risk factors, along with uncertainties, into measures that can be included in estimating variability in expected financial returns, which is the principal metric used in this financial risk analysis. For a typical electric generating unit without carbon capture, construction costs will be incurred during the first few years of the life cycle, operations and maintenance $(\mathrm{O} \& \mathrm{M})$ expenditures will be incurred and receipts will accrue over each year of operations once construction of the plant is completed. If the plant is retrofitted to capture carbon sometime during its useful life, generation will be interrupted temporarily, additional construction expenditures will be 
incurred, and additional O\&M expenditures will be incurred once the retrofit is completed. All of these factors will affect the amount and timing of plant expenditures and revenues over the life cycle of the plant and, over the life cycle of the utility plant with a carbon capture retrofit, will affect the net profitability of the plant. In order to aggregate these revenue and expenditures into a single metric, these annual estimates of revenues and expenditures need to be converted to a common base year. This conversion is done through discounting, which applies an adjustment factor (usually expressed as an interest rate called the discount rate) to revenues and expenditures in each year. For each year, discounted net receipts (revenues less expenditures, discounted) are added up into a final discounted net receipt estimate. It should be noted that the present model is evaluated in the familiar format of an Excel spreadsheet that can be made available to interested users and collaborators.

\section{Technical risk model}

Many inputs into the financial risk model are of the technical type and will be modeled using this new Technical Risk Model. Some of these parameters will come from the process synthesis and design modeling (Task 3), with uncertainties being simulated by the modeling team with input distributions and uncertainty analysis methods defined by the Uncertainty Quantification (UQ) team (Task 6). The marginal distributions for these technical risk factors will then be input into the financial risk model.

Other parameters will not be modeled by the Process Synthesis \& Design Modeling team. To estimate these parameters (including uncertainties), we identified two new modeling efforts:

- Technology Readiness Level (TRL) Risk Model, and

- Qualitative Expert Elicitation Risk Model.

Technical readiness model Measuring a technology's maturity provides one measure that can be an indicator of technical risk. We use the Technology Readiness Level (TRL) scale to estimate the maturity level of our carbon capture technology, on a scale of 1 to 9, as shown in Table 1 (Mankins 1995).

Table 1 Proposed TRL scale for carbon capture

\begin{tabular}{|c|l|l|}
\hline \multicolumn{1}{|c|}{ Technology Readiness Level (TRL) } & \\
\hline 9 & Commercial operation in relevant environment & $650 \mathrm{MW}$ \\
7 & Commercial demonstration, full scale deployment in final form & $>100 \mathrm{MW}$ \\
\hline 6 & Fustem prototype in an operational environment & $10-50 \mathrm{MW}$ \\
\hline 5 & Component validation in relevant environment (coal plant) & $1 \mathrm{MW}$ \\
4 & Component validation tests in laboratory environment & $1 \mathrm{~kW}$ \\
\hline 3 & Analytical and experimental critical function proof-of-concept & \\
2 & Formulation of application & \\
1 & Basic principals & \\
\hline
\end{tabular}

EPRI 2011 (Freeman and Bhown) \& GAO 2010

An uncertainty model has been developed which utilizes the assessed TRL for a given technology (Mathews, 2009). The TRL uncertainty model and sample results are shown in Figure 1. 


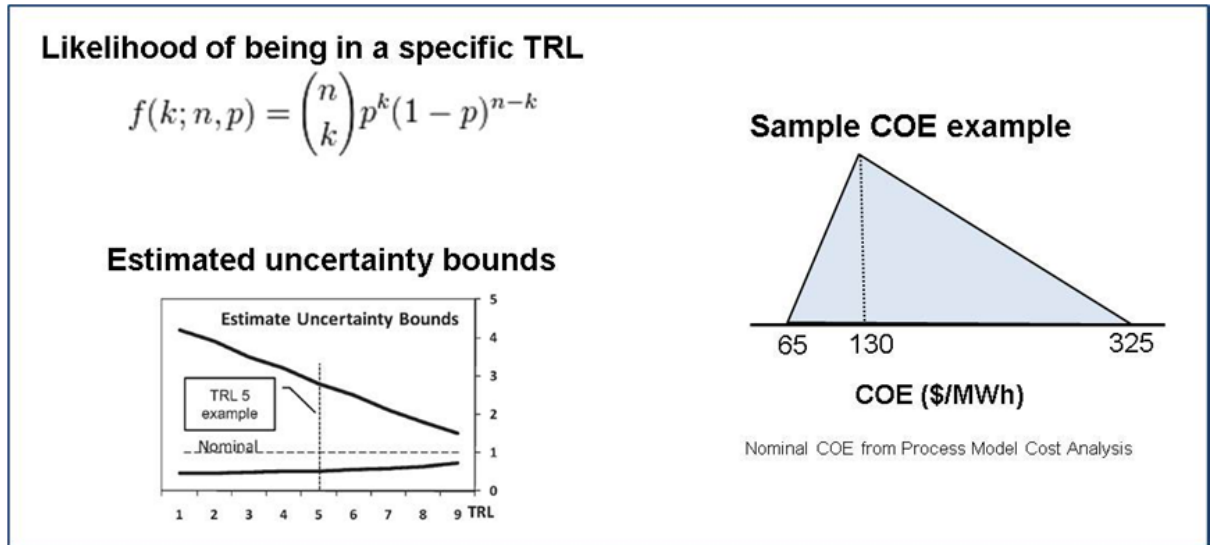

Figure 1 TRL uncertainty model and example using COE from the process modeling task

Expert elicitation model The subtask of Qualitative Expert Elicitation attempts to leverage the diverse expertise of CCSI industry collaborators and national laboratory subject matter experts to capture the range of topical concerns and establish a format for pseudo quantitative ranking. The ranking schema will support comparative prioritization and will facilitate introduction of qualitative risk factors in the financial risk model. Results of the expert elicitation have not been compiled as of yet, and thus will not be included in this initial risk analysis.

Functional system performance The carbon capture risk analyses - financial, technical, and regulatory - depend on the functional performance of the carbon capture system design and operational processes. In particular, the financial model contains cost factors whose values are determined by the equipment design specifications and acceptable operating ranges for system components. However, during the operational lifetime of the plant there can be variations in component behaviors that bias or even contravene the expected performance standards, and hence impact and reshape the cost functions. Based on experience with other large and complex chemical systems, such variations are most likely to occur during the startup and settling-in phase of the lifecycle and during later stages where aging and wearing effects begin to accumulate. Also, at any time there may be components that fail to meet their specified operating performance, or circumstances may conspire among conditions on connected components to negatively affect productivity. Such events are vulnerabilities or risks of the carbon capture plant that can impact financial, technical, and regulatory concerns of interest to decision makers. Managing these risks may be achieved by risk amelioration practices, which, for example, enhance or robustify the design or provide operational and maintenance practices and additional systems to sustain the performance requirements of the carbon capture system.

An initial, heuristic analysis was performed to consider functional system performance issues and their effect on some of the cost functions (Ordorica-Garcia et al., 2006; Schach et al., 2010). Certain stochastic cost parameters expected to be sensitive to variations in functional system performance include: CCS Parasitic Power Requirements; reductions in plant duty cycle or Drop in Capacity Factor; the Carbon Capture Percentage; CCS O\&M costs; and CCS Construction Costs. For example, if the capture process becomes less efficient, the power requirements may have to be increased or the carbon capture drops. Component failure or maintenance needs can reduce the duty cycle and affect O\&M costs. Otherwise, risks may be alleviated by additional construction costs to robustify the design or to build in redundancies.

The variations in system performance are due to functional uncertainties and risks. The uncertainties are associated with distributions of component phenomena determined by variations in key physical 
processes and parameters. As demonstrated by the UQ task group (Task 6) for the MEA carbon capture method, UQ can be developed from an understanding of the underlying physical/chemical processes and from validated or plausible ranges of parameters that determine the behaviors of interest. The risks are characterized by the probability or likelihood of a detrimental occurrence; such as, transient behaviors that do not meet performance specifications, reduction in equipment capabilities or reliability, undue maintenance, and outright component failures. In addition, in the consideration of uncertainties and risks, there are epistemic estimates associated with the qualitative risk factors and with the TRL states-ofaffairs. In the future, information from Task 4 on operational phenomena, monitoring, and control will inform and be informed by the understanding of variations in system performance.

\subsection{Analysis and Results}

The first step of our risk assessment involves creating a baseline net present value calculation without carbon capture (Case A) and an alterative net present value calculation with carbon capture retrofit (Case B). For Case B, NPV estimates were made given a distribution of values for selected factors that vary due to risk and uncertainty. Finally, a comparison of these results (Case A to Case B) is presented.

The next step of the demonstration is to determine which set of factors would be subject to uncertainty. The initial set of factors are shown in Table 2. The factors in this table were selected to demonstrate our methodology since they specifically characterize some of the key technical and financial performance measures of the carbon capture system. The initial nominal values of these variables (factors) were determined from the U.S. Department of Energy and other publications. The initial ranges were determined judgmentally. As the project progresses, additional factors will be included in the financial risk assessment in order to capture a fuller range of technical and financial uncertainties relating to carbon capture.

Table 2 CC system specific parameters: changed under Cases A and B

\begin{tabular}{|c|}
\hline CCS System Specific Parameters \\
Changed Under Case B \\
\hline CCS Parasitic Power Requirements \\
Drop in Capacity Factor due to CCS \\
Carbon Capture Percentage \\
CCS Construction Costs \\
CCS Fixed O\&M Costs \\
\hline
\end{tabular}

The parameters shown in Table 3 have been incorporated into our financial risk model. The values that are highlighted in blue are those model parameters that have the ability to be defined as stochastic (random input values). For the base case (Case A: no carbon capture), the values shown in Table 2 were used for the financial analysis (except for the carbon capture parameters, which were set to zero).

Table 3 Initial financial, operating, and market assumptions

\begin{tabular}{|l|r|r|r|}
\hline Rate, Tax and Growth Assumptions & Value & Units & Source \\
\hline Utility PPA per MWh & 60 & \$ per MWh & Assumption - User Variable \\
\hline PPA Inflation Rate & $1.5 \%$ & Percent & Assumption - User Variable \\
\hline Federal tax rate & $35 \%$ & Percent & Assumption - User Variable \\
\hline State tax rate & $7.0 \%$ & Percent & Assumption - User Variable \\
\hline Discount rate & $7.0 \%$ & Percent & Assumption - User Variable \\
\hline Tax life of plant & 30 & Years & Assumption - User Variable \\
\hline Federal PTC & $0.0 \%$ & Percent & Assumption - User Variable \\
\hline
\end{tabular}




\begin{tabular}{|c|c|c|c|}
\hline Federal ITC & $30.0 \%$ & Percent & Assumption - User Variable \\
\hline State ITC & $7.0 \%$ & Percent & Assumption - User Variable \\
\hline State PTC multiplier & 1 & Units & Assumption - User Variable \\
\hline Electric v. Thermal Power Production & Value & Units & Source \\
\hline Electric Power Output & 650 & MWe & Carbon Capture Project \\
\hline Thermal Power Output & 1,759 & MWth & Thermal to Electric Conversion \\
\hline Replacement Power & Value & Units & Source \\
\hline CCS Parasitic Power Requirements & 192 & MWe & NETL Analysis \\
\hline CCS Parasitic Power Recirculating Fraction & 0.2956 & - & Calculated \\
\hline Plant Average Hours of Operation per Day & 21.9 & hours/day & $\begin{array}{l}\text { Assumption to Meet NETL estimated } \\
85 \% \text { plant capacity factor under CCS }\end{array}$ \\
\hline Plant Average Days of Operation per Year & 340 & days/year & $\begin{array}{l}\text { Assumption to Meet NETL estimated } \\
85 \% \text { plant capacity factor under CCS }\end{array}$ \\
\hline Plant Capacity Factor without CCS & 0.85 & - & Calculated \\
\hline Drop in Duty Factor due to CCS & $5.0 \%$ & percent & Assumption \\
\hline Duty Factor with CCS & 0.800 & - & Assumption \\
\hline Replacement Power Required & 225 & MWe & Assumption \\
\hline Unit Cost of Replacement Power & 60.06 & \$/MWe & Assumption \\
\hline Plant Construction Expenses & Value & Units & Source \\
\hline Total Capital Costs & 1.32 & \$B & NETL (2011, pp 187) \\
\hline Construction Period & 2 & Years & Assumption - User Variable \\
\hline Operating Expenses & Value & Units & Source \\
\hline Operating Expense Inflation Rate & $1.5 \%$ & Percent & Assumption - User Variable \\
\hline Carbon Capture Percentage & $90 \%$ & Percent & Req. of Carbon Capture Project \\
\hline Carbon Tax & 25 & \$ per ton & Assumption - User Variable \\
\hline Fixed O\&M Base Year Cost & 38.7 & $\$ \mathrm{M}$ & NETL (2011) \\
\hline Variable O\&M Cost per mWh & 5.2 & \$ per MWh & $\begin{array}{r}\text { Calculated from NETL Variable Cost } \\
\text { Estimate (2011) }\end{array}$ \\
\hline Fuel Costs per kWh & 0.015 & $\$$ per kWh & NETL (2011) \\
\hline Carbon Capture Retrofit & Value & Units & Source \\
\hline CCS Construction Costs & 0.593 & \$B & From NETL Cost Analysis \\
\hline CCS Fixed O\&M Costs & 53 & $\$ \mathrm{M} /$ year & NETL (2011, pp 176) \\
\hline Variable O\&M Costs & 0.0093 & $\$$ per $\mathrm{kW}$ & NETL \\
\hline Construction Period & 2 & years & Assumption - User Variable \\
\hline
\end{tabular}

For the carbon capture case (Case B), the parameters shown in Table 2 were used as stochastic values. The distributions for these parameters are shown in Figure 2 below. Monte Carlo simulation was used to generate 3000 random values for each of the stochastic parameters, which were then run through the financial model. These parameters were extracted from the system performance simulations (Task 3) and run through the functional systems performance module of the Technical Risk Model. 

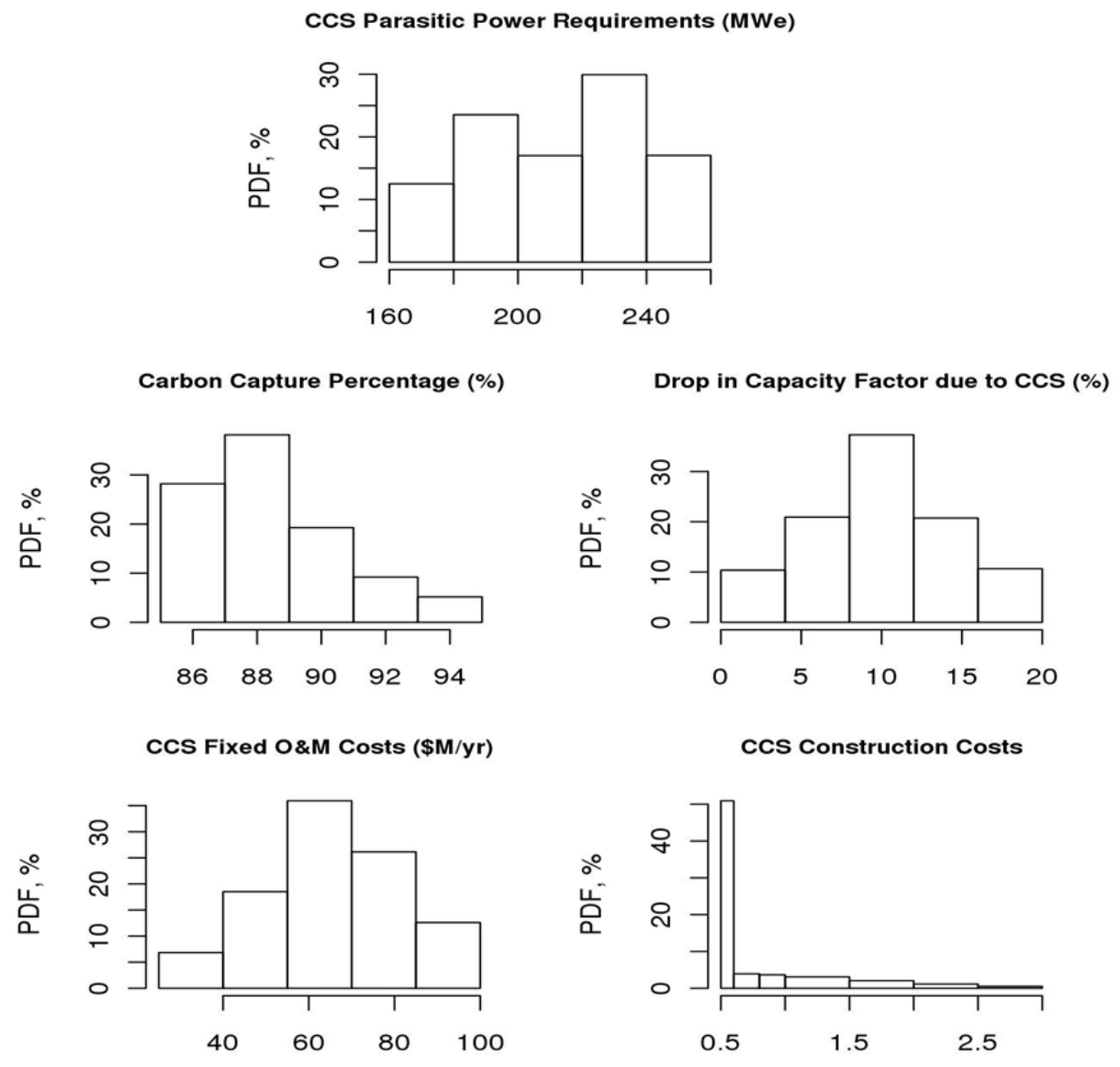

Figure 2 Input marginal distributions for the stochastic parameters

The initial, heuristic analysis was carried out on a hybrid, solid sorbent carbon capture system: A twostage, counter-currently connected bubbling fluidized bed adsorber and a moving bed regenerator, sized for a 650MWe power plant. The details of the sorbent behavior, system design, and some of its attendant phenomena were provided by the Task 2 and 3 teams. The primary observables for system performance were the mass flowrate and the $\mathrm{CO} 2$ loading on the flow stream. These depended on the equipment sizing and temperature and pressure profiles (supported by solid and gas phases mass balance calculations). Through the design process, these teams identified potential system vulnerabilities; such as, parasitic power loss due to steam extraction, particle attrition and distribution, overflow and underflow issues, scaling formation on bed internal manifolds, and abrasion and erosion of component elements. These insights were augmented with literature searches on the performance of solid sorbents which helped to provide some uncertainty ranges (Yi et al., 2007; Sudeshana et al., 2009; Mohanty et al., 2010). Reliability and failure estimates were made on key equipment components based on archived reliability, availability, and maintenance (RAM) information from chemical plants. Additional epistemic measures were included to account for relatively low TRL stages (nominally TRL 3-5) for the system components and to account for some of the qualitative technical risk factors. All these uncertainty and risk measures were then identified as to their functional connection to the selected cost factors discussed above. The pertinent measures were then combined via a probabilistic calculus to aggregate into marginal distributions for the stochastic cost parameters (see Figure 2).

Given the current coarseness of the details and method used to develop the marginal distributions, it is somewhat surprising and pleasing to see some familiar forms emerging. The Drop in Capacity Factor is like a normal; the Carbon Capture Percentage is like a 'fat-tail' (e.g., lognormal or Weibull); and the 
O\&M Costs are a skewed distribution (to higher costs). In retrospect, these forms make some sense. The Parasitic Power Requirements is essentially a bi-modal distribution. In order to maintain an operating capacity and/or capture percentage, the system vulnerabilities may require higher power (less efficiency) to maintain output levels. On the other hand, the vulnerabilities can lead to reduced performance or utility, including some down time, which could lower the parasitic power. These potential couplings among cost factors need to be further explored in our subsequent studies.

The original, or baseline, financial risk analysis assumed uniform distributions over a parameter range. The functional system performance analysis has now added more information to emphasize or diminish certain aspects of the parameter ranges to provide non-uniform distributions. These changes should affect the financial analysis results and provide insights into where uncertainties and risks may be most advantageously reduced to improve the carbon capture enterprise. Refining the analysis and development of these functional performance distributions is a major step in understanding the impacts of uncertainties and risks.

Figures 3 and 4 below show the resulting distributions of discounted net present values under: 1) the assumption that the variables are uniformly distributed; and 2) under the assumption that the variables are subject to the distributions given in Figure 2 above.

As one might expect, the distribution of NPVs of receipts becomes more concentrated around the mean as we move away from uniform distributions. There are, however, some exceptions to this that can be inferred from the distributions given in Figure 2. For example, if the percentage of carbon captured moves from a uniform distribution to the one shown above in the second graph of Figure 2 above, we should expect the NPV of discounted receipts to fall. If less carbon is captured, than more carbon emissions will be subject to carbon taxes causing net receipts to fall in every year. Similarly, if the distribution of CCS constructions moves away from a uniform distribution towards one as shown in the fifth graph in Figure 2 (showing a higher percentage of CCS constructions falling into the lower range of possible values), then we would expect the discounted NPV of receipts to be higher.

In contrast, the CCS parasitic power requirements, the drop in duty factor, and the CCS fixed O\&M costs variables all show distributions that have more probability mass tending to the center of the distribution, relative to the initial uniform distribution. Taken together, these should cause the distribution of discounted NPVs to move towards the mean, as is evidenced when we compare Figures 3 and 4 below.

A sensitivity analysis of the results was performed to identify the stochastic parameters which were correlated with the response variable (NPV). These results are shown in Figure 5. From these results, we can see that four of the five parameters that we simulated showed statistically significant correlation with the NPV. These values were:

- Parasitic Power

- Capacity Factor Drop

- Operating Cost

- Construction Cost 


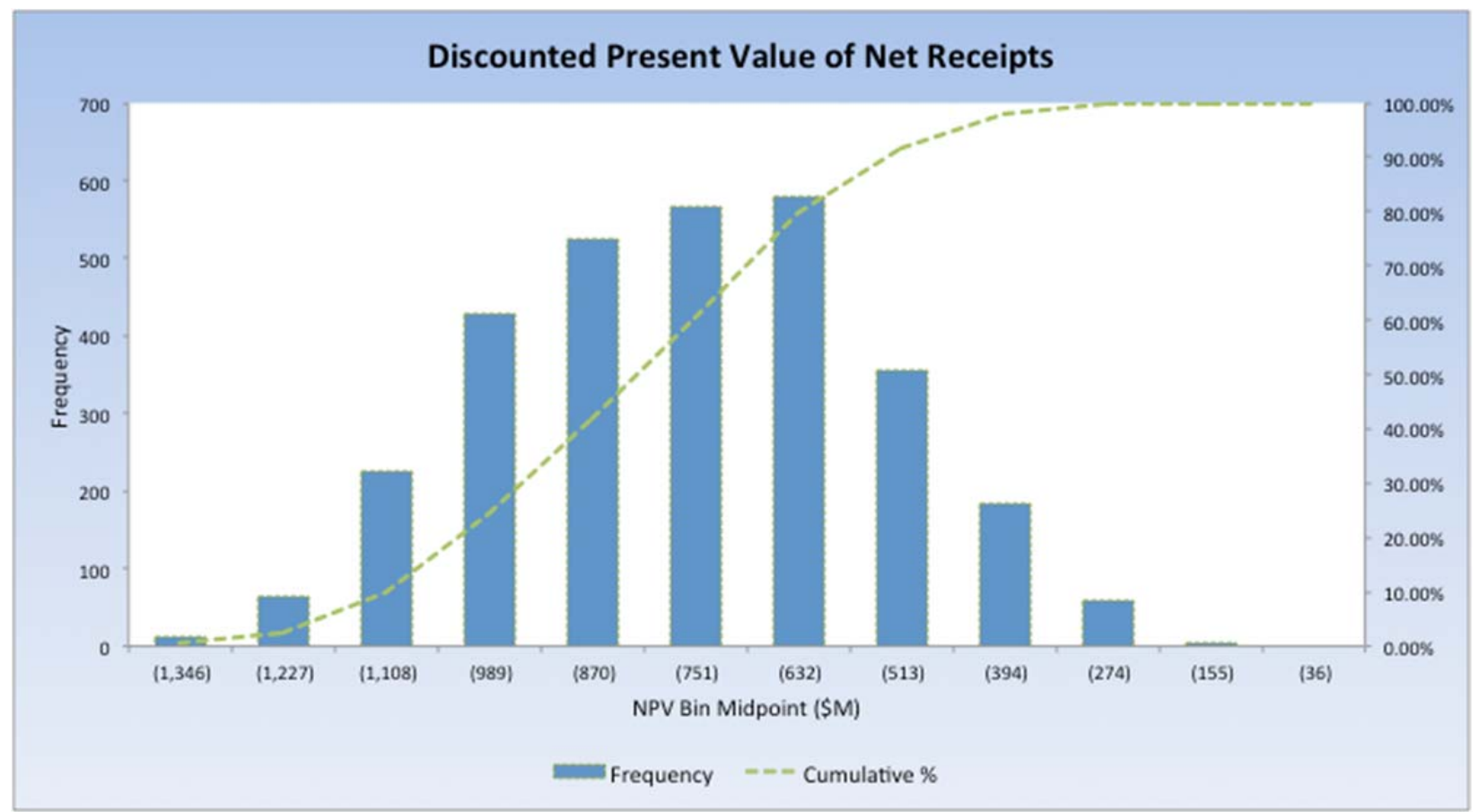

Figure 3 Distribution of discounted net present value of net receipts for the carbon case - uniform distribution of variables

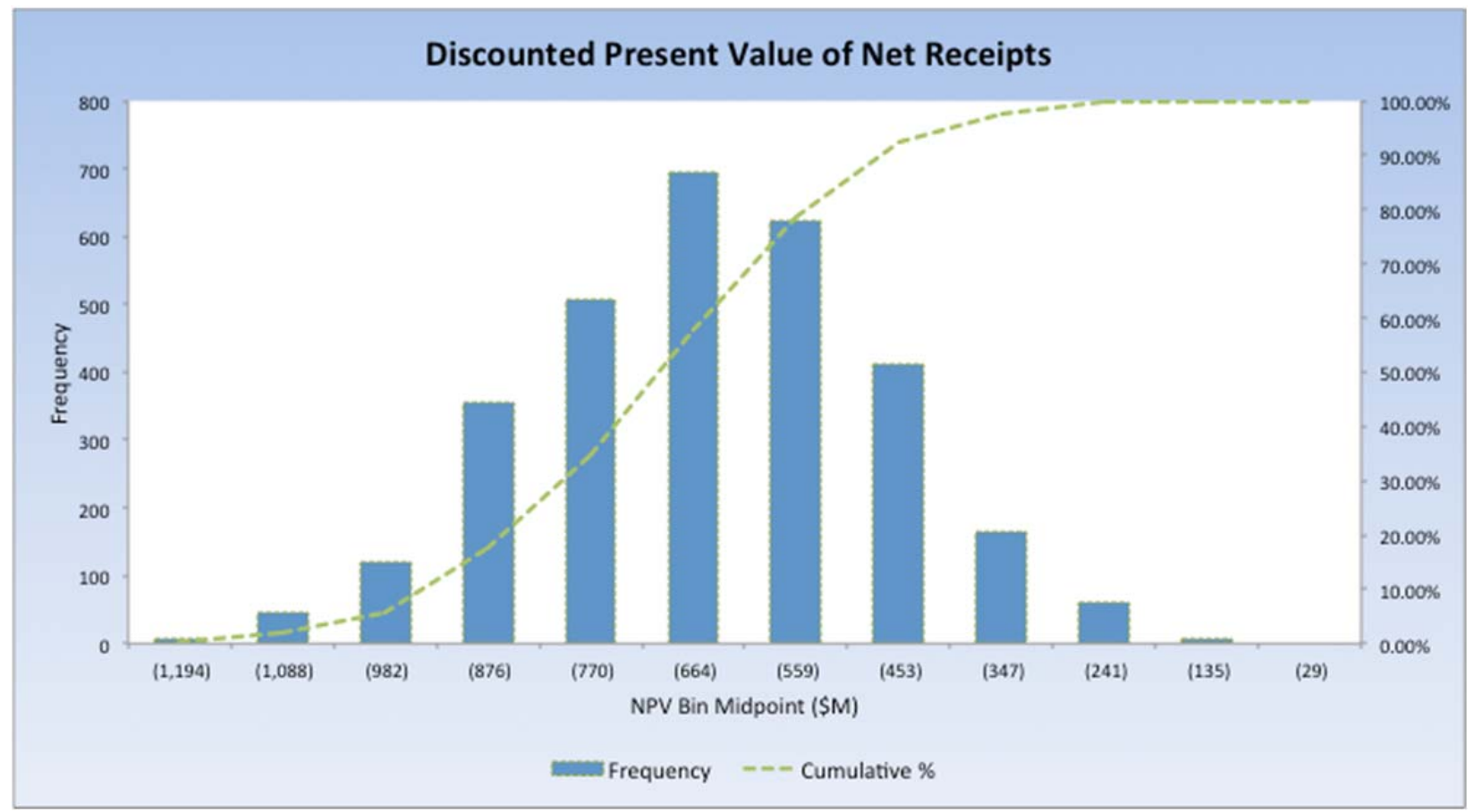

Figure 4 Distribution of discounted net present value of net receipts for the carbon case - non-uniform distribution of variables 

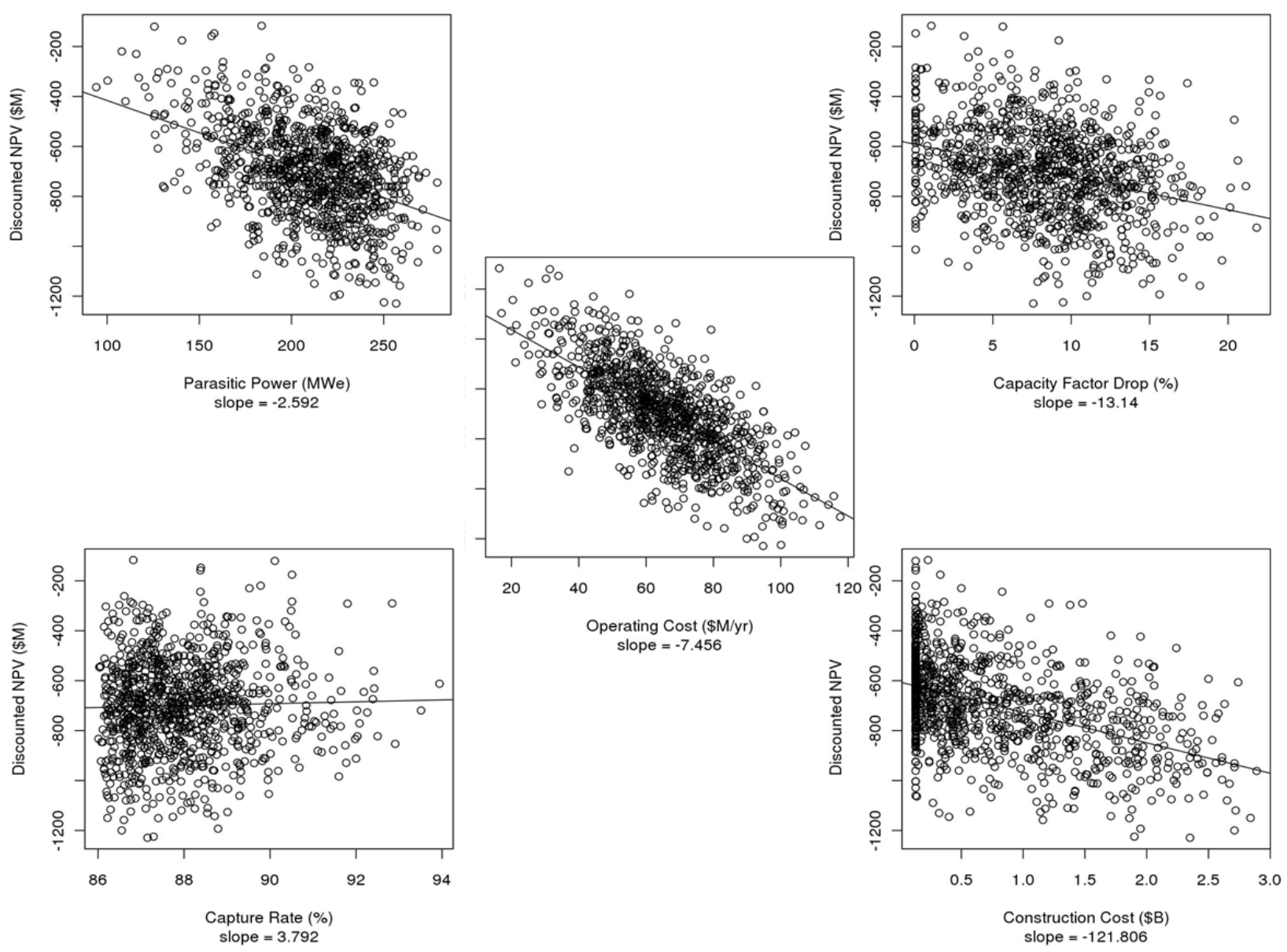

Figure 5 Sensitivity analysis of the NPV, represented by the scatterplots of each NPV-parameter combination

\subsection{Gaps and Path Forward}

Given the preliminary nature of the results of the financial risk model, additional work is required to expand the scope of the model to include additional risk factors, additional information on extant and proposed risk factors, the results of a qualitative risk factor elicitation process, and feedback from utilities and other interested parties involved in the carbon capture project. Additional information on proposed distributions of these risk factors will be integrated into a commercial implementation framework for the purpose of a comparative technology investment analysis. A more detailed analysis of how the distribution of each variable contributes to the distribution of discounted NPV of receipts will be undertaken to support more definitive conclusions from subsequent analysis. Moreover, that sort of detailed analysis is necessary before additional refinements to the model can be undertaken that would allow for analyses of trade-offs between the different factors that affect the level and variation of utility profits and how these will be affected by carbon capture.

For the development of the technical risk model, much time has been spent gathering process information and identifying conceptual models for estimating the key components of the overall technical risk. From 
our initial assessment we have designed the technical risk model into three key modules. Much work is now needed in each of these modules to incorporate information from each of the tasks and also from SME (such as the IAB).

For instance, the specific questions within the TRL model have had an initial review by (CCSI) project members, but will need the input from IAB members. Also, the uncertainty ranges for the likelihood model will need to be developed for the specific technologies. Information from the chemical industry does exist and will be researched.

\subsection{Conclusions}

This report concludes the first year development of the risk analysis and decision making framework. The development team (Team/Element 7) has vast expertise in risk analysis, uncertainty quantification, and financial and economical modeling. The biggest challenge for this team has been learning the specific modeling areas of this industry. While gaining this expertise, a prototype decision making framework (technical and financial) was being designed and implemented. Results of utilizing this framework on a hybrid solid sorbent capture system have been illustrated and discussed. However, what is missing in all of the previous discussion is how this modeling effort will be used within the overall CCSI program and also used by the industry. We attempt, in this section, to touch on this.

A critical part of the utility industry integration is developing contacts with the utility financial analysis community and this will be an important part of year-2 activities. In addition to learning more about the financial metrics used in the industry to evaluate investment alternatives, the team will also engage industry in determining how financial risk is treated in this framework.

The technical risk model is being developed to identify the risk factors that contribute to the overall risk. The goal is to identify those factors that are most important in the risk modeling and thus contribute the most to the overall risk. These key factors can then be passed to the other modeling aspects (elements). For instance the dynamic simulation of the plant operations and control could utilize this information to identify those factors that need to be monitored during the simulation. This information could also drive the UQ analysis (simulation) utilizing these parameters within the system level modeling (process synthesis and design).

\subsection{Reference}

Freeman, BC \& Bhown, AS, Assessment of the technology readiness of post-combustion CO2 capture technologies, Energy Procedia, 4, p.1791-1796, 2011.

Letellier et al., Initial Risk Analysis and Decision Making Framework, CCSI technical report, Nov. 2011.

Mankins, JC, Technology Readiness Levels: A White Paper, NASA, Office of Space Access and Technology, Advanced Concepts Office, 1995.

Mathews, S, Valuing risky projects with real options. Research-Technology Management 52(5): 32-41, 2009.

Mohanty, C.R., Rajmohan, B., and Meikap, B.C., Identification of stable operating ranges of a countercurrent multistage fluidized bed reactor with downcomer, Chemical Engineering and Processing, 49

(2010) 104-112. 
National Energy Technology Laboratory, Cost and Performance of PC and IGCC Plants for a Range of Carbon Dioxide Capture, DOE/NETL-2011/1498, May 27, 2011.

Ordorica-Garcia, G. et al., Technoeconomic evaluation of IGCC power plants for CO2 avoidance, Energy Conversion \& Management, 47 (2006) 2250-2259.

Schach, M-O. et al., Techno-Economic Analysis of Postcombustion Processes for the Capture of Carbon Dioxide from Power Plant Flue Gas, Ind. Eng. Chem. Res. 2010, 49, 2363-2370.

Sudeshna, R., Mohanty, C.R., and Meikap, B.C., Multistage Fluidized Bed Reactor Performance Characterization for Adsorption of Carbon Dioxide, Ind. Eng. Chem. Res. 2009, 48, 10718-10727.

United States General Accounting Office, Coal Power Plants: Opportunities Exist for DOE to Provide Better Information on the Maturity of Key Technologies to Reduce Carbon Dioxide Emissions, Washington D.C.: US GAO, GAO-10-675, 2010.

Yi, C-K. et al., Continuous operation of the potassium-based dry sorbent CO2 capture process with two fluidized-bed reactors, International Journal of Greenhouse Gas Control, 1 (2007) 31-36. 


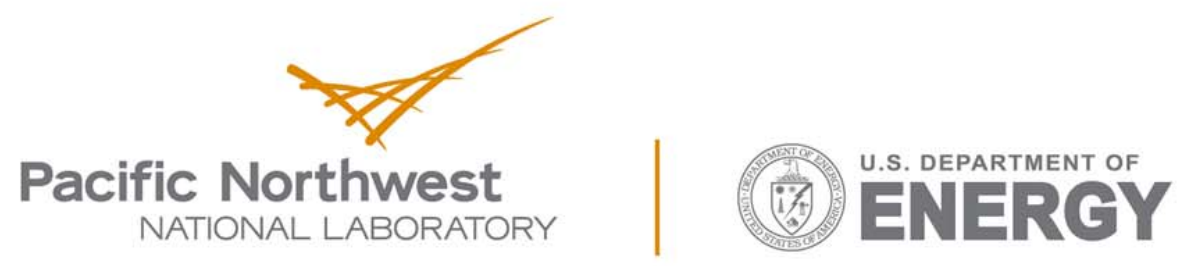

Proudly Operated by Battelle Since 1965

902 Battelle Boulevard

P.O. Box 999

Richland, WA 99352

1-888-375-PNNL (7665)

www.pnnl.gov 